\title{
PREVALÊNCIA DE PNEUMOCONIOSE EM TRABALHADORES EXPOSTOS A ROCHA FOSFÁTICA*
}

\author{
Eduardo Mello De Capitani **
}

\begin{abstract}
DE CAPITANI, E.M. Prevalência de pneumoconiose em trabalhadores expostos a rocha fosfática. Rev. Saúde públ., S.Paulo, 23:98-106, 1989.

RESUMO: Analisou-se a ocorrência de pneumoconiose em trabalhadores ligados à manipulação de rocha fosfática em depósito localizado no Munićpio de Paulínia, Estado de Săo Paulo (Brasil). Entre os 73 trabalhadores expostos a essa matéria prima, constatou-se ocorrência de 20 casos de pneumoconiose $(27,4 \%)$. Após investigação dos casos, constatou-se que os trabalhadores acometidos eram assintomáticos na sua maioria, com provas de função pulmonar pouco alteradas, com predominância de alteraçōes de pequenas vias áereas, com 2 casos com padrão levemente restritivo. A biópsia de pulmão realizada em 2 pacientes não revelou grau de fibrose significativo. A análise do material inalado, através de espectrometria de Raio-X e métodos colorimétricos não evidenciou teor de sílica livre suficiente para promover fibrose pulmonar. Concluiu-se tratar-se de pneumoconiose não fibrogênica, de evolução clínica ainda não conhecida a ser melhor investigada utilizando-se estudos prospectivos. Recomendou-se o afastamento dos trabalhadores acometidos de pneumoconiose e mudanças no processo de trabalho do referido depósito, visando prevenção de novos casos.
\end{abstract}

DESCRITORES: Pneumoconiose, incidência. Exposição ocupacional. Condições de trabalho.

\section{INTRODUÇÃO}

Desde 1981, o Centro de Saúde Escola de Paulínia vem mantendo em funcionamento um programa de assistência à saúde dos trabalhadores ligados a pequenas e médias empresas de Paulínia, município industrial da região de Campinas, Estado de São Paulo (SP) (Costa e De Capitani 4 , 1982). Por intermédio desse Programa, teve-se acesso a diversas empresas que năo dispunham de retaguarda assistencial aos empregados por não se enquadrarem na obrigatoriedade legal. Dentre as empresas participantes do Programa incluia-se um estabelecimento de estocagem e manipulação industrial de rocha fosfática, rocha esta proveniente de minas dos Estados de Góias (GO) e Minas Gerais (MG). Após a estocagem, a maior parte desta rocha segue para $\mathrm{Cu}$ batão, Estado de'São Paulo, onde se localizam as manufaturas de fertilizantes fosfatados.

Dentro do Programa proposto pelo Centro de Saúde-Escola, foi realizada uma inspeção de riscos ocupacionais dentro da empresa, tendo sido propostas diversas modificações no processo de trabalho, na área de depósitos, visando a diminuição ou abolição dos riscos detectados. Dentre as medidas propostas, com relação ao controle médico dos trabalhadores, a telerradiografia periódica de tórax foi colocada como prioritária, tendo em vista o risco inalatório da poeira da rocha fosfática em suspensão nos depósitos e nas áreas de carga e descarga da matéria-prima.

Do ponto de vista geológico, os depósitos de minério de fosfato são classificados em quatro tipos principais (Van Wazer ${ }^{21} 1961$ ), responsáveis pelas jazidas em utilização atualmente no mundo: as apatitas ígneas ou magmáticas, as fosforitas marinhas, as rochas fosfatizadas e o guano. Para a finalidade da presente pesquisa trataremos apenas das apatitas ígneas.

Com relação aos depósitos brasileiros, estes podem ser divididos em dois grupos conforme a classificação acima adotada: os magmáticos e os sedimentares, representados estes últimos pelas fosforitas marinhas, que são depósitos muito antigos associados a fósseis. Entre as jazidas magmáticas mais importantes encontram-se as de Jacupiranga/SP, Catalão/GO, Tapira/MG, Araxá/(MG), Anitópolis/(SC).

Quanto ao aspecto químico, a apatita ou rocha fosfática, tem como fórmula geral $\mathrm{Ca}_{5}(\mathrm{~F}, \mathrm{Cl})$ $\left(\mathrm{PO}_{4}\right)_{3}$. Como componentes outros associados ao

\footnotetext{
* Parte da Dissertação de Mestrado em Saúde Coletiva, apresentada à Faculdade de Ciências Médicas da UNICAMP, em 1987 subordinada ao título "Risco de pneumoconiose em trabalhadores expostos à rocha fosfática".

* Departamento de Medicina Preventiva e Social da Faculdade de Ciências Médicas da Universidade Estadual de Campinas (UNICAMP) - Caixa Postal 6111 - 13081 - Campinas, SP - Brasil.
} 
$\mathrm{P}_{2} \mathrm{O}_{5}$ na rocha fosfática, encontra-se o $\mathrm{CaO}$ na proporção média de $50 \%$; o $\mathrm{MgO}$ com menos de $1 \%$; o $\mathrm{F}_{2} \mathrm{O}_{3}$ por volta de $2,5 \%$; $\mathrm{TiO}_{2} \mathrm{com} 1,5 \%$; $\mathrm{SO}_{3} \mathrm{com}$ menos de $0,5 \% ; \mathrm{Fe}_{3} \mathrm{O}_{4}$ (magnetita) com menos de $0,5 \%$; fluoretos com cerca de $2,0 \%$ e $\mathrm{SiO}_{2}$ (sílica livre) em concentraçðes variando de menos de $1 \%$ até $25,5 \%$ (Abreu, 1973) ${ }^{1}$, dependendo da procedência da amostra e da metodologia de análise. O processo de extração da apatita dá-se em geral a céu aberto. Após a extração existe a necessidade de moagem da rocha com posterior secagem antes da comercialização. Esse processo de moagem e secagem transforma a rocha em pó extremamente fino com características granulométricas semelhantes ao talco, com índice de umidade em torno de $6 \%$. A cor aproxima-se do amarelo palha.

\section{TABELA 1}

Produção de rocha fosfática no Brasil no período 1979 - 1983, em mil toneladas

\begin{tabular}{cc}
\hline Ano & Produção \\
\hline 1979 & 12.478 \\
1980 & 16.533 \\
1981 & 16.441 \\
1982 & 25.070 \\
1983 & 19.898
\end{tabular}

Fonte: Departamento Nacional de Produção Animal

- Divisăo de Extração Mineral (DNPM - DEM)

$\mathrm{Na}$ Tabela 1 vemos a tendência ao crescimento da produção de rocha fosfática no Brasil, comparando dados de 1979 e 1983 . Junto ao crescimento da produção interna houve também uma progressiva substituição quanto às importações chegando a índices de $90 \%$ em 1981, o que se mantém até o momento. A rocha fosfática, anteriormente importada em maiores proporçōes, trazia consigo o risco específico da silicose tendo em vista os teores de silica livre em sua composição (Chauderan ${ }^{3}$, 1983; El Ghawab e Ibrahim 8, 1975; Creteanu e col. ${ }^{5}$, 1969; Pislaru e col. $\left.{ }^{16}, 1969\right)$.

Com relação a distúrbios respiratórios, uma parte da literatura existente não separa metodologicamente os trabalhadores segundo a exposição à poeira de rocha fosfática e outras substâncias químicas, em geral subprodutos da manipulação industrial da rocha, ou mesmo substâncias irritantes de mucosas, existentes nas áreas de fabricação como a amônia, o ácido sulfúrico e o ácido fosfórico. D'Onofrio e col. ${ }^{7}$, em 1954, realizaram investigação numa fábrica de superfosfato na Itália, descrevendo como operação de risco a manufatura de ácido súlfurico destacando o risco de perfuração de septo nasal. Concluíram que a manifestação patológica mais importante era o acometimento irritativo de mucosas rinofaringolaringea que regride à nor- malidade quando se opera o afastamento dos trabalhadores acometidos. Derryberry e col. ${ }^{6} \mathrm{em}$ 1963, num estudo visando avaliação de fluorose em trabalhadores expostos em ambiente de produção de fertilizantes fosfatados, encontraram apenas uma incidência maior de doenças respiratórias quando comparados a grupos controles. Gandevia e Ritche ${ }^{11}$ em 1966, investigaram 18 trabalhadores expostos à poeira de rocha fosfática em silos de estocagem através de provas de função pulmonar, concluindo que existe uma pequena, porém significativa, diminuição na função ventilatória após várias horas de exposição. Não investigaram sequela funcional com tempo de exposição a médio e longo prazos. Não citam casos de pneumoconiose. Creteanu e $\mathrm{col}^{5}$, em 1969, relataram 11 casos de trabalhadores de estradas de ferro na Romênia, expostos a poeira de rocha fosfática com diagnósticos prévios de pneumoconiose caracterizadas etiologicamente até então como siliciose. Dos 11 casos, concluem que 7 podem ser considerados como pordadores de pneumoconiose específica por exposição à apatita, desde que não referiam exposição anterior a outros agentes pneumoconióticos como a sílica livre por exemplo. Evidenciam o aparecimento precoce de alterações radiológicas pulmonares com média de exposição de 27 meses. Observam apenas um caso entre $11 \mathrm{com}$ disfunção ventilatória restritiva. Nada revelam quanto ao teor de sílica no material inalado. Da mesma forma, Pislaru e col. ${ }^{16}$, em 1969, também na Romênia, estudaram do ponto de vista clínico, cerca de 70 trabalhadores expostos a apatita em operaçбes de transporte ferroviário e relatam a ocorrência de 6 pacientes com fibrose pulmonar. Também não avaliam a composição do material inalado. Fabbri e col. ${ }^{10}$, em 1977, encontraram alta prevalência de bronquite crônica $(45,7 \%)$, de deficit funcional respiratório do tipo obstrutivo $(37,1 \%)$, além de dois operários com quadro radiológico compatível com pneumoconiose. Nesse estudo os autores incriminam como agentes etiológicos das patologias respiratórias a poeira de fosforita, o ácido fosfórico e os compostos fluorados subprodutos do processo. Não avaliam teor de sílica livre na pocira inalada. Os mesmos autores ${ }^{9}$, em 1978, confirmam seus próprios resultados em novo estudo com 190 trabalhadores ligados à produção de fertilizantes fosfatados. Encontram alto grau de alterações funcionais e de bronquite crônica nos grupos de trabalhadores ligados à fase de acidulação da rocha fosfática quando são exalados vapores fluorados. Não encontraram casos, de pneumoconiose. Convém ressaltar que Rom e col. ${ }^{18}$, em 1983, em exaustiva e competente revisão sobre pneumoconioses das mais diversas etiologias, não traça qualquer comentário sobre a ocorrência de pneumoconiose ou alterações respiratórias em trabalhadores expostos à poeira de rocha fosfática ou fosforita. 
O objetivo do presente trabalho é descrever a ocorrência de pneumoconiose em trabalhadores ligados à manipulação de rocha fosfática em depósitos do Município de Paulínia, SP.

\section{MATERIAL E MÉTODO}

\section{Sistema de Silagem}

A rocha fosfática manipulada nos depósitos do Muncípio de Paulínia, SP, é extraída e moída em áreas de mineração locálizadas em Catalão/ GO e Araxá/MG, segue por via férrea até Paulínia antes de ser transportada por caminhoes até Cubatão/SP. Em Paulínia ela é estocada em silos horizontais com cerca de $100 \mathrm{~m}$ de comprimento, 40 de largura e 11 a $12 \mathrm{~m}$ de altura e profundidade. Os silos têm forma de losangos num corte transversal com um de seus triângulos subterrâneo. A característica peculiar deste sistema é que o esvaziamento dos silos é feito a partir de seu vértice inferior ou subterrâneo onde se localiza um tubo de concreto de cerca de $160 \mathrm{~cm}$ de diâmetro que percorre toda a extensão dos silos e onde funciona uma esteira rolante que recolhe a matéria-prima de dentro dos depósitos, por gravidade. A operação desta esteira é feita por trabalhadores instalados no interior destes túneis, aí permanecendo em contato direto com à poeira em suspensão durante todo o período de funcionamento das esteiras. $O$ carregamento dos silos também é feito através de esteiras rolantes que se dirigem ao vértice superior dos silos e de lá caem para o interior do sistema. Este não tem nenhuma etapa de enclausuramento, havendo dis- persão de material durante todo o trajeto, desde a descarga dus vagões ferroviários até a carga dos caminhőes que se dirigem a Cubatão (Figura).

\section{População Estudada}

De 103 trabalhadores registrados nos depósitos, 80 deles trabalhavam em áreas de exposição ocupacional à poeira de rocha fosfática, sendo que destes, 73 completaram o estudo que incluiu história clínica com anamnese ocupacional detalhada, exame físico com ênfase no aparelho respiratório, telerradiografia de tórax e prova de função pulmonar. Dois deles submeteram-se à biópsia de pulmão.

\section{História Clínica e Exame Físico}

Foi realizada dentro do tradicional, dando ênfase à anamnese ocupacional para riscos inalatórios e antecedentes mórbidos de distúrbios respiratórios, além de questionamento sobre hábito de fumar.

\section{Prova de Função Pulmonar}

Foram realizadas utilizando-se 0 espirômetro Collins Maxi Survey Computer Systems, obtendo-se no mínimo 3 curvas para cada paciente e adotando-se o critério de variação máxima de $5 \%$ ou $100 \mathrm{ml}$ entre as duas melhores marcas obtidas para a escolha da curva a ser analisada. Segundo Kory e col. ${ }^{14}, 1961$ e Morris e col. ${ }^{15}, 1961$, foram assumidos como valores normais ventilatórios para Capacidade Vital Forçada (CVF\%) sendo maior ou igual a $80 \%$; volume Ex-

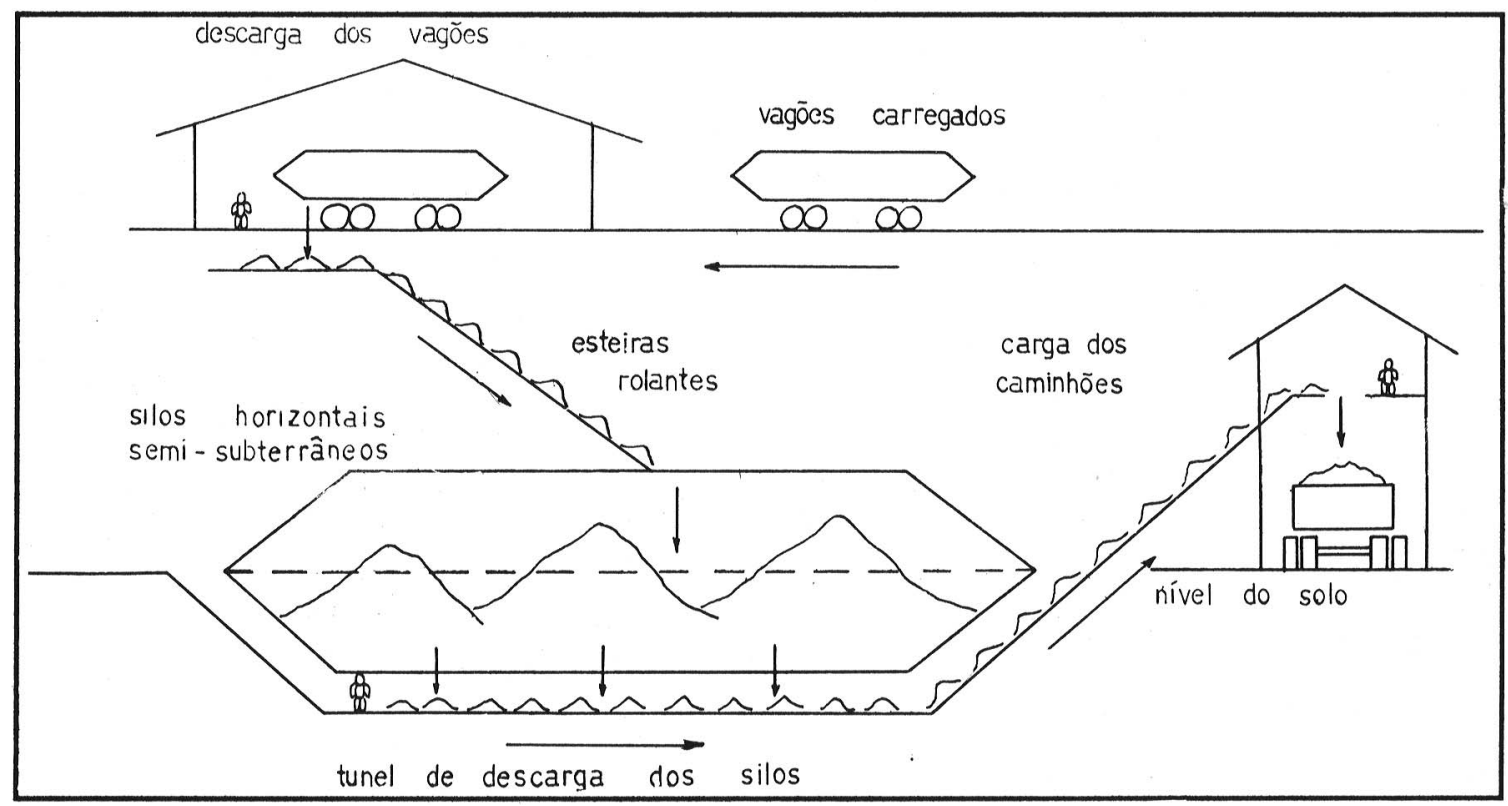

Fig. - Fluxograma do sistema de armazenagem de rocha fosfática. 
piratório Forçado no primeiro segundo na relação $\mathrm{CVF} / \mathrm{VEF}_{1}$ como maior ou igual a $70 \%$ e para os valores referentes ao Fluxo Expiratório Forçado $\left(\mathrm{FEF}_{25-75}\right)$ maior ou igual a $80 \%$.

\section{Radiografia de Tórax}

Como guia diagnóstico e de classificação adotou-se a Classificação Internacional de Radiografias das Pneumoconioses da OIT . Revisão de $1980^{12}$.

As radiografias foram lidas por 3 leitores independentes ( 1 radiologista com especialidade em tórax e experiência em pneumoconiose e 2 médicos do trabalho com larga experiência em leituras nessa área). Foram considerados casos positivos aqueles com parecer e classificação coincidentes ou próximas, emitidos por 2 leitores ao menos.

\section{Biópsia do Pulmão}

Dos vários pacientes estudados e que demonstraram ter exame radiológico alterado, escoIheu-se dois que não possuiam provas de função pulmonar alteradas ou apenas levemente alteradas que não contra indicava a cirurgia. Optou-se por biópsia através de toracotomia com retirada de parte da língula. Os cortes foram incluídos em parafina e corados pelas técnicas do tricrômio de Masson, Van Giensa, além de impregnação.

\section{Avaliação Ambiental}

A composição do material inalado nos postos de maior concentração de poeira foi investigada utilizando-se bomba de aspiração contínua com sistema gravimétrico, portátil, instalada junto ao corpo do trabalhador durante 3 horas contínuas no período de operação de carga e descarga da matéria-prima. O teor de sílica livre foi verificado por método colorimétrico utilizando-se o "Physical and Chemical Analysis Branch". Uma análise semiquantitativa do material foi realizada pelo método de espectrometria de fluorescència de Raios- $X$ utilizando-se EG 86 ORTEC. Foram realizadas 3 amostragens individuais com o dispositivo portátil citado.

\section{RESULTADOS E DISCUSSÃO}

Todos os trabalhdores estudados eram do sexo masculino, sendo $83,6 \%$ de cor branca e $16,4 \%$ de não-brancos.

Situação dos trabalhadores estudados em relação aos postos de trabalho na empresa

A partir da análise do fluxograma operacional da empresa e após uma avaliação preliminar dos postos de trabalho, pudemos detectar 5 postos e situações de trabalho relacionados à exposição à poeira de rocha fosfática em diversos graus de intensidade, conforme descrito na Tabela 2.

\section{TABELA 2}

Definição do grau de intensidade de exposição à rocha fosfática conforme o posto de trabalho. Município de Paulínia, SP, 1981

$\begin{array}{ll}\text { Posto de Trabalho ou } & \text { Grau de Intensidade } \\ \text { Atividade dentro } & \text { de Exposição } \\ \text { da Empresa. } & \text { à rocha Fosfática. }\end{array}$

1. Descarga dos vagões ferroviários.

forte

2. Operações de carga de caminhōes: operação dentro dos túneis.

grave

3. Operação da coifa na carga dos caminhões.

forte

4 Tratorista no pátio de manobras dos vagões.

leve

5. Encarregado de setor ou auxiliar de encarregado.

moderado

As operações de descarga de vagões e de carga direta dos caminhőes no manejo da coifa ( 1 e 3 da Tabela 2), apesar de apresentarem excessivo grau de exposição, são diferenciadas da operação de carga no interior dos túneis subterrâneos onde a exposição, mais que grave, é dramática.

\section{TABELA 3}

Prevalência de pneumoconiose segundo o posto de trabalho ou atividade dos trabalhadores estudados. Município de Paulínia, 1981.

\begin{tabular}{lccc}
\hline $\begin{array}{l}\text { Posto de } \\
\text { Trabalho } \\
\text { ou Atividade } \\
\text { dentro da } \\
\text { Empresa }\end{array}$ & $\begin{array}{c}\text { Pessoas } \\
\text { Estudadas }\end{array}$ & $\begin{array}{l}\text { Prevalência de } \\
\text { Pneumoconiose }\end{array}$ \\
\hline $\begin{array}{l}\text { 1. Descarga dos } \\
\text { vagões ferro- } \\
\text { viários. }\end{array}$ & 45 & 4 & 8,8 \\
$\begin{array}{l}\text { 2. Operação de } \\
\text { carga de caminhões: } \\
\text { operação dentro } \\
\text { dos túneis }\end{array}$ & 11 & 8 & 72,7 \\
$\begin{array}{l}\text { 3. Operação da } \\
\text { coifa na carga } \\
\text { dos caminhões }\end{array}$ & 6 & 5 & 83,3 \\
$\begin{array}{l}\text { 4. Tratorista no } \\
\text { pátio de manobras } \\
\text { dos vagões }\end{array}$ & 3 & - & - \\
$\begin{array}{l}\text { 5. Encarregado de } \\
\text { setor ou auxiliar de } \\
\text { encarregado. }\end{array}$ & 8 & 3 & 37,5 \\
\hline \begin{tabular}{l} 
Total \\
\hline
\end{tabular} & 73 & 20 & 27,4 \\
\hline
\end{tabular}


Na tabela 3 analisamos a distribuição dos trabalhadores estudados e dos casos de pneumoconiose segundo a atividade e os postos de trabalho. Da análise desta Tabela 3 depreende-se, primeiramente, que as operaçס̄es de maior risco ocupacional são as de carga dos caminhores, tanto quando se trabalha dentro dos túneis subterrâneos, como na operação da coifa na carga direta (postos 2 e 3 da Tabela 3).

Dos 11 trabalhadores estudados na ocupação $\mathrm{n}^{2} 2,8$ apresentaram pneumoconiose em algum grau de evolução $(72,7 \%)$. Este dado coincide com a qualidade da exposição atribuída aos postos de trabalho que constam na Tabela 2. Da mesma forma, mas em proporção maior, temos a ocorrência de 5 casos de pneumoconiose em 6 estudados na operação $n^{\ell} 3(83,3 \%)$. Esta coincidência não ocorre em relação à operação de descarga de vagóes onde, de 45 trabalhadores estudados ocorreram apenas 4 casos de pneumoconiose $(8,8 \%)$. Apesar de ter sido qualificado como um posto de forte exposição, a ocorrência de pneumoconiose foi pequena. Isto parece dever-se ao fato de essa operação congregar trabalhadores iniciando-se na empresa, como porta de entrada para outras operaçőes, aí permanecendo um tempo médio menor. O grau de dispensa nessa atividade também é alto, caracterizando-se um subgrupo instável e de alta rotatividade. A atividade de $n^{2}$ 5 , na Tabela 3, encarregado de setor ou auxiliar de encarregado, diz respeito à funçăo de supervisão e controle das diversas áreas do sistema, ocorrendo exposição variável, desde muito intensa, quando da supervisão aos postos 1, 2 e 3, até pouco intensa quando a atividade se restringe ao pátio de manobras ou áreas a céu aberto. A ocorrência de 3 casos de pneumoconiose em 8 nessa atividade parece estar ligada ao passado profissional dos irabalhadores, sendo que 2 deles trabalharam durante 50 e 57 meses, respectivamente, na operação de carga no interior dos túneis, daí passando à função de encarregado, ocupada à epoca da investigação.

\section{TABELA 4}

Prevalência de pneumoconiose segundo a idade dos trabalhadores. Município de Paulínia, 1981

\begin{tabular}{lccc}
\hline Idade em Anos & $\begin{array}{l}\text { Trabalhadores } \\
\text { Estudados }\end{array}$ & \multicolumn{2}{c}{$\begin{array}{l}\text { Prevalência de } \\
\text { Pneumoconiose } \\
\text { No }\end{array}$} \\
\hline 30 & 35 & 4 & 11,4 \\
$30 \longrightarrow 50$ & 19 & 7 & 36,8 \\
$40 \longrightarrow 60$ & 16 & 7 & 43,7 \\
$50 \longrightarrow 6$ & 3 & 2 & 66,6 \\
60 e mais & - & - & - \\
\hline Total & 73 & 20 & 27,4 \\
\hline
\end{tabular}

Idade

A Tabela 4 refere-se à distribuição dos casos com pneumoconiose segundo a idade. Nota-se tendência aparente de aumento na proporção de casos de pneumoconiose com a idade, com $11,4 \%$ de casos na faixa etária de 20 e 30 anos subindo para $66,6 \%$ na faixa de 50 a 60 anos. O quesito idade, porém, deverá ser ponderado tendo-se em conta o fato de existir uma certa tendência a pneumopatia crônica nos pacientes com mais idade, com mais anos de hábito tabágico $\mathrm{e}$, em nosso caso específico, de serem os trabalhadores mais velhos os que trabalham há mais tempo expostos e nos setores de mais alto risco.

\section{TABELA 5}

Prevalência de pneumoconiose segundo o tempo de exposição à rocha fosfática. Município de Paulínia, 1981

\begin{tabular}{lccc}
\hline $\begin{array}{l}\text { Tempo de } \\
\text { Exposição } \\
\text { em Meses }\end{array}$ & $\begin{array}{l}\text { Trabalhadores } \\
\text { Estudados }\end{array}$ & \multicolumn{2}{c}{$\begin{array}{l}\text { Prevalência de } \\
\text { Pneumoconiose } \\
\text { Ne }\end{array}$} \\
\hline $0-14$ & 39 & 3 & 7,6 \\
24 & 20 & 8 & 40,0 \\
48 & 11 & 7 & 63,6 \\
$72-1$ & 2 & 66,6 \\
\hline e mais & 3 & 20 & 27,4 \\
\hline
\end{tabular}

\section{Tempo de Exposição}

$\mathrm{Na}$ tabela 5 percebe-se uma tendência crescente e importante a partir de 2 anos de exposição com prevalência de $40 \%$ na faixa de 24 a 48 meses, subindo para $66 \%$ na faixa de 72 meses e mais, lembrando que a empresa estava em funcionamento há cerca de 7 anos à época da investigação. A média do tempo de exposição entre os trabalhadores acometidos pela pneumoconiose foi de 46 meses com uma variação limite de 12 a 73 meses com mediana em 36 meses. Dados referentes aos estudos de Creteanu e col. 5 e Pislaru e col. ${ }^{16}$ mostram tempo médio de aparecimento de imagens radiológicas compatíveis com pneumoconiose de 24 a 36 meses, em ambos os trabalhos. Convém ressaltar, em relação a essa variável que, tanto os trabalhos citados quanto o atual estudo são investigações de corte transversal ou de prevalência não podendo fornecer qualquer tipo de dado mais real quanto ao tempo de exposição médio necessário ao surgimento de imagens citadas, dado este possível de ser obtido apenas em estudos longitudinais, de seguimento de coortes expostas.

\section{Hábito de fumar}

No grupo estudado como um todo verificou-se a quase equivalência entre tabagistas $\mathrm{e}$ não-tabagistas $(54,7 \%$ e $45,3 \%$, respectivamente), - mesmo ocorrendo entre os acometidos por pneumoconiose ( $45 \%$ e $55 \%$, respectivamente). $O$ 
mesmo padrão foi encontrado entre o trabalhadores estudados por Creteanu e col. ${ }^{5}$.

\section{TABELA 6}

Distribuição dos casos de pneumoconiose segundo as ocupaçōes anteriores à exposiçăo a rocha fosfática. Município de Paulínia, 1981

\begin{tabular}{|c|c|c|}
\hline \multirow{2}{*}{$\begin{array}{l}\text { Ocupações anteriores à } \\
\text { exposiç̧̃o a rocha } \\
\text { fosfática }\end{array}$} & \multicolumn{2}{|c|}{ Casos de Pneumoconiose } \\
\hline & $\mathrm{N}^{\mathrm{e}}$ & $\%$ \\
\hline \multirow{7}{*}{$\begin{array}{l}\text { Lavoura } \\
\text { Lavoura + Construção } \\
\text { Civil } \\
\text { Lavoura + Porto de Areia } \\
\text { Lavoura + Usina de } \\
\text { Açúcar } \\
\text { Construção Civil + Fabrica- } \\
\text { çăo Fertilizantes + Garim- } \\
\text { po de Pedras Preciosas }\end{array}$} & 14 & 70,0 \\
\hline & 2 & \\
\hline & $\begin{array}{l}3 \\
1\end{array}$ & $\begin{array}{r}15,0 \\
50\end{array}$ \\
\hline & & \\
\hline & 1 & 5,0 \\
\hline & & \\
\hline & 1 & 5,0 \\
\hline Total & 20 & 100,0 \\
\hline
\end{tabular}

\section{Ocupaçöes anteriores}

A Tabela 6 traz os dados referentes a essa variável. Constata-se a baixa qualificação dos trabalhadores acometidos, sendo que $14 \mathrm{em} 20$ (70\%) deles provinham diretamente da lavoura. Dos 6 restantes apenas 2 provinham de atividades industriais anteriores. Desta forma, excetuando-se - paciente que trabalhou anteriomente em fábrica de fertilizantes, a exposição prévia a agentes pneumoconióticos que porventura estivesse se sobrepondo ao quadro pulmonar atual, não se evendenciou no grupo acometido.

\section{Sintomatologia Respiratória e Ausculta Pulmonar}

Não referiram qualquer sintoma respiratório 85\% dos pacientes acometidos. Dispnéia foi mencionada por 3 pacientes e relacionada em dois deles ao tempo de permanência em contato com a poeria no ambiente de trabalho. $O$ terceiro paciente com dispnéia apresentava cardiopatia crônica hipertrófica, em tratamento, o que limita o dado em relação ao aparelho respiratório. Nenhum paciente apresentava queixas compatíveis com broncoespasmo, seja no ambiente de trabalho, seja fora dele. O mesmo ocorria com os sintomas de tosse crônica com expectoração ou sem ela, apesar do número razóavel de fumantes dentre eles (45\%). Esses dados são discrepantes com relação aos achados de Creteanu e col. ${ }^{5}$ que de 11 casos diagnosticados, referiu 9 com dispnéia e dor tóracica além de 5 casos com tosse sem referência à produção de escarro. A ausculta pulmonar criteriosa não evidenciou qualquer anormalidade exceto pelo achado de estertoração crepitante unilateral em estreita faixa de base pulmonar no paciente portador de cardiopatia.

\section{TABELA 7}

Distribuiçăo dos 20 casos de pneumoconiose segundo $c$ tipo de defeito funcional apresentando o seu grau de intensidade de alteração. Município de Paulínia, 1981

\begin{tabular}{|c|c|c|c|c|c|}
\hline $\begin{array}{l}\text { Tipo de } \\
\text { Alteração } \\
\text { Funcional }\end{array}$ & $\begin{array}{l}\text { Grau } \\
\text { Leve }\end{array}$ & $\begin{array}{l}1 \text { de intensic } \\
\text { Moderado }\end{array}$ & $\begin{array}{l}\text { dade } \\
\text { Grave }\end{array}$ & $\mathrm{N}^{2}$ & $\% *$ \\
\hline $\begin{array}{l}\text { Obstrutivo } \\
\text { (alteração no } \\
\text { VER } / \text { CVF) }\end{array}$ & 2 & 1 & - & 3 & 15,0 \\
\hline $\begin{array}{l}\text { Restritivo } \\
\text { (alteração } \\
\text { no CVF\%) }\end{array}$ & 1 & 1 & - & 2 & 10,0 \\
\hline $\begin{array}{l}\text { Alterações de } \\
\text { fluxos } \\
\text { expiratórios } \\
\text { (alterações } \\
\text { no FEF 25-75) }\end{array}$ & 3 & 7 & 4 & 14 & 70,0 \\
\hline $\begin{array}{l}\text { Misto - } \\
\text { (obstrutivo + } \\
\text { restritivo) }\end{array}$ & - & - & - & - & - \\
\hline Normal & - & - & - & 5 & 25,0 \\
\hline
\end{tabular}

* Os valores percentuais levaram em conta a existência de simultaneidade de alteraçōes.

\section{Provas de Função Pulmonar}

Dos 20 pacientes acometidos, 15 (75\%) tiveram alteraçסes em suas provas ventilatórias. Defeito tipo obstrutivo foi observado em 3 pacientes (15\%), a partir de alteraçð̃es na relação $\mathrm{VEF}_{1} / \mathrm{CVF}$ (Tabela 7). Alterações de fluxos expiratórios de leve para grave intensidades, diagnóstico fornecido pela análise do FEF $25-75 \%$ foram observados em 14 pacientes (70\%). Dos dois casos com defeito restritivo (10\%), um deles apresentou concomitantemente alterações graves de fluxos expiratórios. Nota-se assim o grande predomínio de alterações de fluxos expiratórios correspondendo a defeitos em pequenas vias aéreas, alterações estas que podem ser consideradas como precoces dentro de um processo evolutivo de acometimento funcional (Morris e col. 15, 1973; Sobol e col. ${ }^{19}, 1973$; Knudsen e col. ${ }^{13}$ 1976).

Creteanu e col. ${ }^{5}$ demonstraram alteraçoes funcionais em sua casuística na proporção de 7 para 11 trabalhadores com pneumoconiose. Houve predomínio obstrutivo em 6 dos 7 alterados, com um caso de déficit restritivo. Em nossa casuística não pudemos observar, assim como Creteanu e col. 5 , nenhuma correlação entre os diagnósticos da função pulmonar e a sintomatologia ou mesmo o aspecto radiológico. Opacidades com valoração elevada quanto à classifi- 
cação por tamanho e profusão nem sempre correspondiam a uma prova de função pulmonar alterada. $O$ mesmo pode-se dizer quanto ao tempo de exposição. Pacientes com tempos de exposição limites com 12 meses e 73 meses apresentavam déficits de função pulmonar próximos, sendo que em 5 casos com provas normais, os tempos de exposição eram de 19, 29, 36, 38 e 62 meses, em postos de trabalho considerados como de forte (dois casos) e grave (três casos) intensidades de exposição.

\section{Alteraçōes Radiológicas}

As alteraçбes radiologicas restringiram-se a pequenas opacidades com predomínio quanto à sua forma arrendondada em 17 dos 20 casos (85) (Tabela 8). Não houve qualquer alteração extraparenquimatosa, não tendo-se observado doença nas pleuras ou imagens alteradas em mediastino. Estes achados coincidem com a literatura disponível, que embora não caracterizem as alterações radiológicas pelo padräo das Classificações Internacionais, descreve-as como "micronodulações parenquimatosas pulmonares bilaterais em ter-ços médios, sem alterações de pleura ou de mediastino" (Creteanu e col. 5 , 1969; Pislaru e col. ${ }^{16}, 1969$ ).

\section{TABELA 8}

Distribuição dos casos de pneumoconiose segundo o tipo das alterações radiológicas pulmonares. Município de Paulínia, 1981

\begin{tabular}{lcrrr}
\hline Alterações Radiológicas & & N & $\%$ \\
\hline & & $\mathrm{p}$ & 10 & 50,0 \\
Pequenas & Arrendondadas & $\mathrm{q}$ & 7 & 35,0 \\
Opacidades & Irregulares & $\mathrm{s}$ & 1 & 5,0 \\
& & $\mathrm{t}$ & 2 & 10,0 \\
\hline & Total & & 20 & 100,0 \\
\hline
\end{tabular}

\section{Alteraçōes Histopatológicas}

O exame anátomo-patológico das duas peças de biópsias realizadas mostrou o parênquima pulmonar com extensos depósitos de cristalóides castanho-enegrecidos com refrigência focal à luz polarizada, de localização perivascular, peribrônquica, septal e intra-alveolar. Circunjacente a esses depósitos observou-se colapso alveolar com leve reação inflamatória, predominantemente histiocitária. Apesar da utilização de colorações como o tricrômio de Masson, Van Gienso, impregnação argêntica para fibras de reticulina, além da $\mathrm{HE}$, não se evidenciou fibrose significativa. A desproporção entre a carga de material cristalóide depositada e o grau praticamente nulo de fibrose, foi um dado marcante no estudo anátomo-patológico. As tentativas de identificação dos cristais depositados no tecido pulmonar não surtiram resultados com a utilização da microscopia bptica. Estudos de idenficação de material inorgânico presente em tecidos têm sido realizados utilizando-se técnicas compostas de microscopia eletrônica, tanto de transmissão quanto de varredura, associadas à difração de Raios-X (Berry e col ${ }^{2}, 1976$; Vallyathan e col. ${ }^{20}$, 1980.)

\section{TABELA 9}

Elementos constituintes das amostras de rocha fosfática analisados por expectrometria de Raios-X.

\begin{tabular}{crr}
\hline Elementos & \multicolumn{2}{c}{ Procedência das amostras } \\
\cline { 2 - 3 } Detectados & Catalāo (GO) & Araxá (MG) \\
\hline $\mathrm{Ca}$ & ++++ & ++++ \\
$\mathrm{P}$ & + & + \\
$\mathrm{Fe}$ & +++ & +++ \\
$\mathrm{Mn}$ & + & + \\
$\mathrm{Sr}$ & ++ & ++ \\
$\mathrm{Ti}$ & + & + \\
$\mathrm{Ba}$ & & + \\
$\mathrm{Nb}$ & + & + \\
$\mathrm{S}$ & + & \\
\hline
\end{tabular}

\section{Análise da poeira inalada}

A Tabela 9 traz os diversos elementos químicos encontrados na análise por espectrometria de Raios- $X$ segundo as duas procedências das rochas manipuladas. Os resultados desta análise são semiquantitativos sendo a variação de cada elemento representada em cruzes ( $\mathrm{de}+\mathrm{a}++++$ ). Convém ressaltar que o Fluor (F), elemento seguramente constituinte das duas amostras, desde que seus subprodutos são detectados na manipulação industrial dessas rochas, não aparece na análise em função da pouca resolução do método para este tipo de elemento. Fenômeno semelhante acontece com o fósforo (P) que apesar de estar ligado ao cálcio na forma de fosfatos, o pico de fósforo resultante da análise mostra-se pequeno. Apesar do método ter boa resolução para sîlica-livre, não houve detecção desta substância em nenhuma das amostras.

\section{Determinação do teor de Sílica}

$\mathrm{O}$ teor de sílica-livre $\left(\mathrm{SiO}_{2}\right)$ determinado por método químico através de colorimetria nas amostras de ambas as rochas não chegou a $1 \%$.

\section{COMENTÁRIOS FINAIS}

A presente investigação detectou, na população exposta estudada, 20 casos de pneumoconiose relacionados à exposição à poeira de rocha 
fosfática, indicando uma prevalência para o grupo de trabalhadores expostos de $27,4 \%$.

O estudo histopatológico de dois dos 20 casos detectados mostrou tratar-se de pneumoconiose sem componente fibrogênico de importância. Segundo definição do grupo de trabalho reunido na $4^{2}$ Conferência Internacional de Pneumoconiose 17 , em 1971, classifica-se entre as pneumoconioses não colagênicas. No entanto, os cortes histológicos analisados mostram uma desestruturação dos componentes histológicos pulmonares, com destruição de septos alveolares e uma intensa deposição de cristais nos tecidos intersticiais e dentro dos espaços alveolares, o que torna preocupante o prognóstico desses casos quanto à função pulmonar, a médio e longo prazo, caso persista a exposição.

Do ponto de vista da etiologia da pneumoconiose, a discriminação óptica dos cristais e as características histopatológicas encontradas nos cortes de biópsia não permitem qualquer definição de especificidade. Entretanto, alguns pontos podem ser levantados: 1 . O teor de sílica livre $\left(\mathrm{SiO}_{2}\right)$ encontrado nas amostras do material inalado foi quantificado como menor que $1 \%$ permitindo caracterizar a pneumoconiose como provavelmente não silicótica. 2 . A ausência de fibrose significativa no exame anátomo-patológico corrobora a afirmação anterior. 3 . Tendo em vista o alto teor de sais de cálcio na composição do material inalado (mais de $50 \%$ em média), pode-se inferir sobre a provável composição dos cristais visualizados no histopatológico, prováveis responsáveis pelas imagens radiológicas, como sendo predominantemente de sais de cálcio e em menor proporção de outros metais radiopacos. 4. Somente a análise histopatológica com microscopia eletrônica de varredura, associada a microanálise por difração de Raio-X, poderá determinar precisamente a composição dos cristais depositados nos tecidos.

Tendo em vista a não comunicação até o momento de casos de pneumoconiose devido à exposição à poeira de rocha fosfática no Brasil, e mesmo os poucos casos relatados na literatura internacional, apesar de ser matéria prima manipulada há mais de 30 anos em quase todo o mundo, acredita-se que a magnitude da prevalência de casos positivos encontrada na presente investigação relaciona-se, em sua maior parte, às condições de trabalho na empresa em questão, que favorecem grau de exposição extremamente intenso comprometendo de forma dramática a capacidade de "clearance" pulmonar.

Ressalta-se o papel de importância que os serviços de saúde, voltados ao atendimento geral da população, têm em relação aos aspectos específicos da saúde ocupacional e ambiental. $O$ presente estudo, originado de um programa de assistência à saúde dos trabalhadores de pequenas e médias empresas de Paulínia, reflete a necessidade $e$ a exeqüibilidade da integração de atividades de saúde ocupacional no atendimento de adultos nas unidades de saúde responsáveis pelo atendimento primário de uma dada população.

O anacronismo da legislação atual, referente à fiscalização e mudanças nos ambientes de trabalho, aliados à debilidade da organização sindical de alguns setores profissionais, fizeram com que poucas alteraçōes ocorressem nas condiçōes de trabalho da empresa em questão, apesar da notificação das três partes diretamente envolvidas, ou seja, os trabalhadores, a empresa e os órgãos fiscalizadores (Ministério do Trabalho e Secretaria das Relações do Trabalho do Estado de São Paulo).

Como recomendações foram propostas alteraçōes técnicas do processo de trabalho na carga dos caminhőes, visando a diminuir e até a abolir o risco naquela área. O afastamento imediato dos trabalhadores acometidos e o controle médico rigoroso do restante, com prova de função pulmonar periódica, tendo em vista alterações precoces nesse exame, e telerradiografia de tórax, no mínimo anualmente. Como medida administrativa propôe-se redução para carga horária de trabalho mais civilizada e compatátivel com a lei, além de rodízio constante nas áreas de maior risco.

\section{AGRADECIMENTOS}

Aos Drs. Paulo Roberto de Madureira, Nelson Rodrigues dos Santos, René Mendes pelo incentivo, apoio e orientação do trabalho. Aos Drs. Silvio Rezende, Ivan Contrera Toro e José Geraldo dos Santos da Disciplina de Pneumologia da Faculdade de Ciências Médicas. Às Dras. Cecília Amélia F. Escanhoela e Mirian Trevisan, da Disciplina de Anatomia Patológica da Faculdade de Ciências Médicas da UNICAMP. Aos Drs. Nelson A.M. Garrafa e José Luiz C. Marins pela leitura radiológica criteriosa e ao Luiz Antônio Borges pela avaliação ambiental e análise da composição do material inalado. 
DE CAPITANI, E.M. [Prevalence of pneumoconiosis among workers exposed to phosphate rock]. Rev. Saúde públ., S.Paulo, 23:98-106, 1989.

ABSTRACT: The occurrence of pneumoconiosis among workers at a phosphate rock mill in Paulinia, S.Paulo(Brazil), is analysed. Among the 73 exposed workers the occurrence of 20 cases of pneumoconiosis $(27.4 \%)$ is registered. Beyond the physical examination, the investigation included spirometric examination, thorax X-rays, and lung biopsies during thoracotomy. The majority of the pneumoconiotic workers were assymptomatic with mild alterations in the spirometric pattern, mainly in the maximal medium expiratory flow, with 2 cases of restrictive pattern. The two lung biopsies did not reveal any degree of fibrosis and the analysis of the inhaled material, using $X$-ray spectrometry and colorimetric method, did not show enough $\mathrm{SiO}_{2}$ to promote fibrosis. It is concluded that the pneumoconiosis in question must be included in the non-fibrogenic group until further investigation can be made, by prospective research.

KEYWORDS: Pneumoconiose, occurrence. Occupational exposure. Working conditions.

\section{REFERÊNCIAS BIBLIOGRÁFICAS}

1. ABREU, S.F. Recursos minerais do Brasil. São Paulo, Ed. Edgar Blucher, 1973. v.1.

2. BERRY, J.P. et al. Pulmonary mineral dust. Amer. J.Path., 83: 427-38, 1976.

3. CHAUDERAN, J. Phosphates, superphosphates. In: Enciclopaedia of Occupational Health and Safety. 3rd. ed. Geneva, 1983, p. 1679-80.

4. COSTA, J.L.R. \& DE CAPITANI, E.M. Assistência à saúde nas pequenas e médias empresas. In: CongressoNacional de Prevenção de Acidentes do Trabalho, 20, São Paulo, 1982. Anais. São Paulo, FUNDACENTRO, 1982. p.343-48.

5. CRETEANU, G.H. et al. Consideratii aspura unos cazuri de pneumoconioze la apatita la muncitori feroviari. Riv. Medicochir. Iasi, 73:837-42, 1969.

6. DERRYBERRY, O.M. et al. Fluoride exposure and worker health. Arch. environm Hlth., 6:503-11, 1963.

7. D'ONOFRIO, V. et al. Osservazioni sulla patologia professionale di operai addetti alla produzione di superfosfati. Rass. Med. industr. 6:369-78, 1954.

8. EL GHAWABI, S. H. \& IBRAHIM, S.M. Pneumoconiosis in the superphosphate industry. Egypt. J. occup. Med., 3: 55-62, 1975.

9. FABBRI, L. et al. Broncopneumopatia cronica e pneumoconiosi in operai addetti alla produzione di acido fosforico. Lav. Um., 28: 50-7,1977.

10. FABBRI, L. et al. Patologia respiratoria del ciclo di produzione de fertilizzanti fosfati. 2 - Bronchite cronica ed alterozione funzionale respiratorie. Med. Lavoro, 69: 723$27,1978$.

11. GANDEVIA, B. \& RITCHIE, B. Relevance of respiratory symptoms and signs to ventilatory capacity changes after exposure to grain dust and phosphate rock dust. Brit. $J$. industr. Med., 23: 181-7, 1966.
12. INTERNATIONAL LABOR OFFICE. Guidelines for the use of ILO - International Classification of Radiographs of Pneumoconioses; Revised ed. Geneva, 1980.

13. KNUDSEN, $R$. et al. The Maximal expiratory flow volume curve: its use in the detection of ventilatory abnomalities in a population study. Amer. Rev. resp. Dis., 114: 871-9, 1976

14. KORY, R.C. et al. The veterans Adm-Army Cooperative study of pulmonary function. I-Clinical spirometric in normal man. Amer. J. Med., 30:243-58, 1961.

15. MORRIS, J.F. et al. Spirometric standards for the non smoking adults. Amer. Rev. resp. Dis., 103: 57-67, 1971.

16. PISLARU, V. et al.Riscul de imbolnavire la apatitá in trasportul feroviar. Riv. Medicochir. Iasi., 73: 961-6, 1969.

17. REPORT of the working group on definitions of pneumoconioses. In: International Pneumocosiosis Conference, 4th, Bucharest, 1971. Proceedings. Bucharest, Apinonda Publ., 1971. p. 786-8.

18. ROM, W.N. et al. Other occupational lung diseases. In: Rom, W.N., ed. Environmental and occupational medicine. Boston, Little, Brown and Co. 1983. p. 251-66.

19. SOBOL, B.J. et al. Relative value of various spirometric tests in the early detection of chronic obstructive disease. Amer.Rev. resp. Dis., 107:753-62, 1973.

20. VALLYATHAN, F.H.Y. et al. Recent advances in the study of mineral pneumoconiosis. Path Ann., 15: 77. $104,1980$.

21. VAN WAZER, J.R. Phosphorus and is compounds. New York, Interscience Publ., 1961.

Recebido para publicaçāo em 3/5/1988

Reapresentado em 1/2/1989

Aprovado para publicaçäo em 10/2/1989 